\title{
The value of diagnostic hysteroscopy with biopsy in the preoperative of endometrial ablation
}

\author{
0 valor da histeroscopia diagnóstica com biópsia no pré-operatório de ablação endometrial
}

\author{
Salete Yatabe ${ }^{1}$, Ana Maria Gomes Pereira ${ }^{1}$, Gilberto Kendi Takeda ${ }^{1}$, \\ Daniela de Baptista Depes ${ }^{1}$, Reginaldo Guedes Coelho Lopes ${ }^{1}$
}

\begin{abstract}
Objective: To assess the value of diagnostic hysteroscopy with biopsy in the preoperative preparation for endometrial ablation. Methods: It was a prospective non-randomized study conducted at the division of Gynecologic Endoscopy of Hospital do Servidor Público Estadual "Francisco Morato de Oliveira" from March 2007 to May 2009. A total of 45 patients with abnormal uterine bleeding, and referred to endometrial ablation were included. All women underwent a diagnostic hysteroscopy, and were treated with a $\mathrm{GnRH}$ analogous - goserelin - $10.8 \mathrm{mg}$ before surgery. The endometrial ablation was performed with a surgical resectoscope. Patients were submitted to one directed endometrial biopsy, one guided endometrial biopsy with Novak curette, and to endometrial ablation, which was considered as reference for pathological examination with samples from the biopsies. Data were analyze using the SPSS-v16 software, and considered significance at $p=0.05$. Results: The mean age of women was 44.20 years (33-56), parity of $2.67(0-9)$, uterus size of 139.99 calculated in cc (42-278), and the mean duration of symptoms was 3.68 years $(0.5-15)$. The guided endometrial biopsy showed sensitivity of $80 \%$ for endometrium without atypia, and the directed endometrial biopsy had sensitivity of $60 \%$. For proliferative endometrium the directed endometrial biopsy showed sensitivity of 76 and $100 \%$ for secretory endometrium, which was higher than the guided endometrial biopsy with 53 and $50 \%$, respectively. Conclusion: The directed biopsy before endometrial ablation had lower sensitivity than guided biopsy for endometrium without atypia, however it was higher for proliferative and secretory endometrium.
\end{abstract}

Keywords: Biopsy; Endometrium; Hysteroscopy/instrumentation; Hysteroscopy/methods

\section{RESUMO}

Objetivo: Analisar o valor da biópsia de endométrio no pré-operatório de ablação endometrial. Métodos: Estudo prospectivo não randomizado realizado no setor de Endoscopia Ginecológica do Hospital do Servidor Estadual "Francisco Morato de Oliveira" de março de 2007 a maio de 2009, de 45 pacientes encaminhadas por sangramento uterino anormal com indicação de ablação do endométrio. Todas as pacientes tinham histeroscopia diagnóstica prévia à cirurgia e receberam análogo de $\mathrm{GnRH}$ - goserelina - 10,8 mg subcutânea no pré-operatório. A ablação de endométrio foi realizada com ressectoscópio cirúrgico. Foram realizadas: uma biópsia dirigida, uma biópsia orientada com cureta de Novak e, em seguida, a ablação, enviando-se o produto dessa (considerado como referência) e o das biópsias para exame anatomopatológico. 0 teste exato de Fisher foi utilizado para comparar os três tipos de biópsia. Nível de significância foi estabelecido em $p=0,05$. Resultados: A média de idade das pacientes foi de 44,20 anos (33-56), paridade de 2,67 filhos (0-9), volume uterino 139,99 cc (42-278) e sintomas em anos média de 3,68 (0,5-15). A biópsia orientada apresentou para endométrio sem atipias maior sensibilidade (80\%) que a biópsia dirigida (60\%). Para o resultado de endométrio proliferativo e secretor, a biópsia dirigida apresentou sensibilidade de 76 e 100\%, respectivamente, superior à orientada (53 e 50\%). Conclusão: $\mathrm{A}$ biópsia dirigida prévia à ablação do endométrio tem menor sensibilidade que a orientada para endométrio sem atipias, porém maior para endométrio proliferativo e secretor.

Descritores: Biópsia; Endométrio; Histeroscopia/instrumentação; Histeroscopia/métodos

\section{INTRODUCTION}

Abnormal uterine bleeding is an important health problem among reproductive-aged women, in the peri and postmenopausal period so that it can reduce their quality of life and increase anemia.

Most patients have benign affections, excluding those with dysfunctional uterine bleeding. Focal intrauterine lesions, mainly endometrial polyps and submucous myomas, are common gynecological conditions that affect 30 and $9 \%$, respectively, of patients with abnormal

\footnotetext{
Study carried out at the Division of Gynecologic and Endoscopy of the Hospital do Servidor Público Estadual "Francisco Morato de Oliveira" - HSPE-FMO, São Paulo (SP), Brazil.

"Hospital do Servidor Público Estadual "Francisco Morato de Oliveira" - HSPE-FMO, São Paulo (SP), Brazil.

Corresponding author: Salete Yatabe - Hospital do Servidor Público Estadual - Rua Pedroso de Toledo, 1800 - $4^{0}$ andar - Vila Clementino - CEP $04039-020$ - São Paulo (SP), Brazil - Tel.: 11 5088-8085 -E-mail: fyatabe@uol.com.br

Received on: May 5, 2011 - Accepted on: Oct 25, 2011

Conflict of interests: none
} 
uterine bleeding ${ }^{(1)}$. All symptomatic patients over 35 years of age must be evaluated and even earlier if they have risk factors like obesity or chronic anovulation ${ }^{(2)}$. Clinical treatment alone is not enough to discard intrauterine diseases. In addition, it is recommended to obtain endometrial material for pathological examination.

Clinical treatment could be an option, however, results are frequently unsatisfactory and sometimes is contraindicated. Hysterectomy is efficient to stop bleeding, but it constitutes a large surgery with some complications intrinsic to the procedure ${ }^{(3)}$.

Endometrial ablation constitutes a surgical technique that destroys or dries the endometrium. It is indicated for cases of abnormal uterine bleeding that do not present improvement with clinical treatment, or when this treatment is contraindicated.

This technique is an alternative for hysterectomy to treat benign diseases being less aggressive and invasive, with low morbidity and mortality, and at a lower cost.

The pre-existing medical condition to endometrial ablation is the assurance that the endometrium does not present any preneoplastic or neoplastic lesion. Hence, diagnostic hysteroscopy and endometrial biopsy are recommended before submitting the patient to surgery.

For a long time, uterine curettage (CTG) was the method to obtain endometrial sample for histopathological diagnosis. This procedure has pitfalls and requires hospital admission and anesthesia. Its complication rate is $2.7 \%$, and in $60 \%$ of procedures it evaluates less than a half of the uterine cavity ${ }^{(4,5)}$. In addition, it fails to detect intrauterine abnormalities as polyps, myomas and focal lesion suspected of malignancy. The negative-false rate is 2 to $10 \%{ }^{(5)}$.

The endometrial biopsy could be done at outpatient clinics using devices as Pipelle and Novak curette, although they present similar problems to CTG due to false negative results. Other devices to obtain endometrial sampling are: Tao Brush, a brush to analyze endometrium that in general is painless for patients when compared with suction biopsy; ultrasound-directed endometrial biopsy, which does not improve results compared with Pipelle; and Nicoletti-Gorlero device for directed endometrial biopsy by hysterosonography ${ }^{(4)}$.

Systematic reviews and meta-analyses on diagnostic hysteroscopy in several comparative studies between hysteroscopy and pathological results obtained during surgical hysteroscopy or by directed endometrial biopsy in pre- and postmenopausal women with abnormal uterine bleeding, confirmed that this technique is safe, had few complications and good accuracy to diagnosis of uterine affections ${ }^{(6,7)}$.

Sensitivity of hysteroscopy to diagnose endometrial hyperplasia using visual criteria is of $65 \%$ in premenopausal women, $61 \%$ in postmenopausal women and $86.4 \%$ to diagnose cancer even when the endometrium is atrophic and the risk of cancer is $0.7 \%$.

Hysteroscopy should follow the biopsy as a routine in all cases of distorted uterine relief or endometrial appearance, since hysteroscopy visualisation cannot replace histopathology ${ }^{(8)}$.

Diagnostic hysteroscopy with directed endometrial biopsy is considered the gold standard in abnormal uterine bleeding evaluation, because it allows direct and accurated visualisation of the uterine cavity to evaluate possible affections. The final result of the diagnostic hysteroscopy is the combination of endoscopic test with the pathological examination of the endometrial biopsy.

\section{OBJECTIVE}

To compare results from pathological examination of endometrial biopsy with results of the pathological analysis of endometrial ablation product.

\section{METHODS}

A prospective non-randomized study was conducted at division of Gynecologic Endoscopy of Hospital do Servidor Público Estadual "Francisco Morato de Oliveira" (HSPE-FMO) from March 2007 to May 2009. The study was approved by the Research and Ethics Committee of HSPE-FMO under the no 026/07; the informed consent was given to the 45 patients with abnormal uterine bleeding and who were referred for endometrial ablation.

Patients were submitted to diagnostic hysteroscopy before and on the day of the surgery. Participants were treated with subcutaneous GnRH analogous goserelin $-10.8 \mathrm{mg}$ in the preoperative preparation of the endometrium, and also to improve hemoglobin levels in those with anemia.

We used for endometrial ablation the wire-loop surgical resectoscope $26 \mathrm{~F}$ with potency of 90 watts and glycine of $1.5 \%$ related to uterine cavity distension.

Before the surgery and with the patient already anesthetized, a diagnostic hysteroscopy was performed with directed endometrial biopsy of the anterior wall of the endometrium using Bettocchi hysteroscopy with accessory canal and biopsy forceps. Subsequently, the cervical canal was dilated and endometrial ablation was done.

The material collected from both biopsies and the ablation product were submitted to pathological examination. In cases that polyps were found we did a polipectomy before the ablation, and the polyps examined separately. 
For statistical analysis, the Statistical Package for Social Sciences v. 16.0 was used. The Fisher exact test was used to compare frequencies and proportions of the types of biopsies. The significant level was established as 0.05 or $5 \%$.

\section{RESULTS}

A total of 45 patients with abnormal uterine bleeding and referred to endometrial ablation were included. Descriptive analysis with quantitative variables is shown in table 1 . The mean age of women was 44.2 years (33-56), parity of 2.67 (0-9), uterus size of 139.99 calculated in cc (42-278), and the mean duration of symptoms was 3.68 years $(0.5-15)$.

The comparison among directed endometrial biopsy, ablation and the percentage of ablation data concordance in relation to directed endometrial biopsy

Table 1. Descriptive analysis: quantitative variables

\begin{tabular}{lcccccc}
\hline Variables & $\mathbf{n}$ & Mean & $\begin{array}{c}\text { Standard } \\
\text { deviation }\end{array}$ & Medium & Minimal & Maximum \\
\hline Age & 45 & 44.20 & 5.09 & 44.00 & 33.00 & 56.00 \\
Parity & 45 & 2.67 & 1.48 & 2.00 & 0.00 & 9.00 \\
Symptoms & 45 & 3.68 & 3.17 & 3.00 & 0.50 & 15.00 \\
Uterine volume & 45 & 139.99 & 56.69 & 134.00 & 42.00 & 278.00 \\
\hline
\end{tabular}

Year olds/symptoms: length of years/uterine volume calculated in cc. is shown in table 2 . The directed endometrial biopsy had $60 \%$ of sensitivity for endometrium without atypia, $76 \%$ for proliferative endometrium and $100 \%$ for secretory endometrium.

Table 3 shows the comparison between guided biopsy, ablation and the percentage of ablation data concordance in relation to guided endometrial biopsy. Guided endometrial biopsy had $80 \%$ of sensitivity for endometrium without atypia, 53\% for proliferative endometrium and $50 \%$ for secretory endometrium.

\section{DISCUSSION}

Considering the pathological results from ablation as reference, guided endometrial biopsy showed $80 \%$ of sensitivity and $73 \%$ of specificity for the endometrium without atypia. The directed endometrialbiopsyachieved sensitivity of $60 \%$ and specificity of $78 \%$. Guided biopsy presented higher sensitivity to endometrium without atypia. For proliferative endometrium and secretory endometrium a higher sensitivity was seen with directed endometrial biopsy.

For proliferative endometrium the guided endometrial biopsy had $53 \%$ of sensitivity and $86 \%$ of specificity, whereas directed endometrial biopsy had $76 \%$ of sensitivity and $71 \%$ of specificity. For secretory endometrium the guided endometrial biopsy had $50 \%$

Table 2. Comparison among directed biopsy, ablation and percentage concordance of ablation toward direct biopsy

\begin{tabular}{|c|c|c|c|c|c|c|}
\hline \multirow{2}{*}{ Directed biopsy } & \multicolumn{6}{|c|}{ Ablation } \\
\hline & & Endometrium without atypia & Proliferative & Secretory & Total & Fisher's exact test \\
\hline \multirow[t]{2}{*}{ Endometrium without atypia } & $n$ & 3 & 9 & 0 & 12 & 0.01 \\
\hline & $\%$ ablation & 60 & 23.7 & 0.0 & 26.7 & \\
\hline \multirow[t]{2}{*}{ Proliferative } & $\mathrm{n}$ & 2 & 29 & 0 & 31 & \\
\hline & $\%$ ablation & 40 & 76.3 & 0.0 & 68.9 & \\
\hline \multirow[t]{2}{*}{ Secretory } & $\mathrm{n}$ & 0 & 0 & 2 & 2 & \\
\hline & $\%$ ablation & 0.0 & 0.0 & 100 & 4.4 & \\
\hline \multirow[t]{2}{*}{ Total } & $n$ & 5 & 38 & 2 & 45 & \\
\hline & $\%$ ablation & 100 & 100 & 100 & 100 & \\
\hline
\end{tabular}

We observed a statistical difference was observed between guided biopsy and ablation in the Fisher's exact test $(\mathrm{p}<0.05)$.

Table 3. Comparison among guided biopsy, ablation and percentage concordance of ablation toward guided biopsy

\begin{tabular}{|c|c|c|c|c|c|c|}
\hline \multirow{2}{*}{ Guided biopsy } & \multicolumn{6}{|c|}{ Ablation } \\
\hline & & Endometrium without atypia & Proliferative & Secretory & Total & Fisher's exact test \\
\hline \multirow[t]{2}{*}{ Endometrium without atypia } & $n$ & 4 & 11 & 0 & 15 & 0.03 \\
\hline & $\%$ ablation & 80 & 28.9 & 0.0 & 33.3 & \\
\hline \multirow[t]{2}{*}{ Proliferative } & $n$ & 1 & 20 & 0 & 21 & \\
\hline & $\%$ ablation & 20 & 52.6 & 0,0 & 46.7 & \\
\hline \multirow[t]{2}{*}{ Secretory } & $n$ & 0 & 1 & 1 & 2 & \\
\hline & $\%$ ablation & 0.0 & 2.6 & 50 & 4.4 & \\
\hline \multirow[t]{2}{*}{ Polyps } & $n$ & 0 & 6 & 1 & 7 & \\
\hline & $\%$ ablation & 0.0 & 15.8 & 50 & 15.6 & \\
\hline \multirow[t]{2}{*}{ Total } & $n$ & 5 & 38 & 2 & 45 & \\
\hline & $\%$ ablation & 100 & 100 & 100 & 100 & \\
\hline
\end{tabular}


of sensitivity and $98 \%$ of specificity, and the directed biopsy had $100 \%$ of sensitivity and $100 \%$ specificity.

Despite the use of the GnRH analogous prior to surgery there were two cases of secretory endometrium. In the guided endometrial biopsy seven cases of polyps were reported, however, none was found in ablation or directed endometrial biopsy. It could be explained because directed endometrial biopsy was directed to endometrium and deviated from polyps. In the ablation, polypectomy was previously conducted, and the material obtained from polypectomy was examined separately from ablation product.

Histological result of endometrium without atypia was characterized when the pathologist could not define exactly the type of the endometrium, although the analyzed amount was considered sufficient. There was no case of insufficient material, even when the material was obtained by directed endometrial biopsy. A study of 1,276 biopsies by Bettochi et al. with hysterocospy of small-diameter using $5 \mathrm{~F}$ instruments stated that directed biopsy, when adequate instruments and the appropriated technique are used, allows the pathologist to obtain enough material (mean $5.7 \mathrm{~mm}$ ) to hystopathological examination ${ }^{(9)}$.

A study comparing hystopathological results using hysteroscopy with directed endometrial biopsy and guided endometrial biopsy from patients treated with tamoxifen found $80 \%$ specificity and $68.9 \%$ positive predictive value for directed endometrial biopsy and $68.9 \%$ specificity and $43.7 \%$ positive predictive value for guided endometrial biopsy. For the distinction between normal and abnormal endometrium, hysteroscopy showed sensitivity and negative predictive values of $100 \%$ independent of the type of biopsy done. They concluded that in women taking tamoxifen, endomentrial assessment using guided endometrial biopsy appeared to be safe to exclude hyperplasia or cancer; the directed endometrial biopsy allowed better evaluation ${ }^{(7)}$.

A total of 639 women was evaluated with outpatient diagnostic hysteroscopy followed by endometrial biopsy with Novak curette. The accuracy of guided endometrial biopsy was compared with hysteroscopy for intrauterine lesions. Using the Novak curette false negative values were $88.7 \%$ to detect polyps and $98.5 \%$ for submucous myomas with sensitivity of $8.4 \%$ and $1.4 \%$, respectively. Diagnostic hysteroscopy with endometrial biopsy increases accuracy, and enables to diagnose almost all focal lesions of the uterine cavity ${ }^{(1)}$.

The specificity of guided endometrial biopsy with the Novak curette was compared with directed endometrial biopsy using hysteroscopy in 319 patients by Angioni et al. in order to detect benign intracavitary lesions as the cause of postmenopausal bleeding. From this total, $67 \%$ of participants had endometrial affections. The guided endometrial biopsy in this study showed sensitivity of $11 \%$ and specificity of $93 \%$ with accuracy of $59 \%$ to detect polyps. For submucous myoma it presented sensitivity, specificity and accuracy of $13 \%, 100 \%$ and $98 \%$, respectively. Hysteroscopy in the same study had sensitivity of $100 \%$, specificity of $97 \%$, and accuracy of $91 \%$ for polyps, for submucous myoma it showed sensitivity of $100 \%$, specificity of $98 \%$ and accuracy of $99 \%$. In conclusion they stated that guided endometrial biopsy had low sensitivity and accuracy to diagnose focal intracavitary lesions. Besides that, hysteroscopy proved to eliminate the guided endometrial biopsy false negative results and allowed directed endometrial biopsy in cases of doubt ${ }^{(10)}$.

\section{CONCLUSION}

The pathological examination of endometrial ablation product compared with guided endometrial biopsy and directed endometrial biopsy showed higher sensitivity for endometrium without atypia for guided biopsy, and higher sensitivity to proliferative and secretory endometrium for directed biopsy.

\section{REFERENCES}

1. Svirsky R, Smorgick N, Rozowski U, Sagiv R, Feingold M, Halperin R et al. Can we rely on blind endometrial biopsy for detection of focal intrauterine pathology? Am J Obstet Gynecol. 2008;199:115.e1-.e3.

2. Goldstein SR. Modern evaluation of the endometrium. Obstet Gynecol. 2010;116(1):168-76.

3. Lethaby A, Hickey M, Gary R, Penninx J. Endometrial ressection/ablation techniques for heavy menstrual bleeding. Cochrane Database of Sys Rev. 2009; (4) CD001501

4. Revel A. Multitasking human endometrium. A review of endometrial biopsy as a diagnostic tool, therapeutic applications and a source of adult stem cells. Obst Gynecol Surv. 2009;64(4):249-57.

5. Tinelli R, Tinelli FG, Cicinelli E, Malvasi A, Tinelli A. The role of histeroscopy with eye-directed biopsy in postmenopausal women with uterine bleeding and endometrial atrophy. Menopause. 2008;15(4):737-42.

6. Van Dongen H, Croon CD, Jacobin CE, Tribes JB, Jansen FW. Diagnostic hysteroscopy in abnormal uterine bleeding: a systematic review and meteanalysis. BJOG. 2007;114(6):664-75.

7. Garuti G, Cellani F, Colonnelli M, Garzia D, Gonfiantini C, Luerti M. Hysteroscopically targeted biopsies compared with blind samplings in endometrial assessment of menopausal women taking tamoxifen for breast cancer. J Minim Invasive Gynecol. 2004;11(1):62-7.

8. Costa H de L, Costa LO. Hysteroscopy in menopause: analysis of the techniques and accuracy of the method. Rev Bras Ginecol Obstet. 2008;30(10):524-30

9. Bettocchi S, Venere RD, Pansini N, Pansini MV, Pellegrino A, Santamato S et al. Endometrial biopsies using small-diameter hysteroscopy's and 5 F instruments: how can we obtain enough material for a correct histological diagnosis? J Minim Invasive Gynecol. 2002;9(3):290-2.

10. Angioni S, Loddo A, Milano F, Piras B, Minerba L, Melis GB. Detection of Benign intracavitary lesions in postmenopausal women with abnormal uterine bleeding: A prospective comparative study on outpatient hysteroscopy and blind biopsy. J Minim Invasive Gynecol. 2008;15(1):87-91. 